\title{
STUDY OF PLASTIC DEFORMATION OF CADMIUM
}

\author{
I.I. Papirov ${ }^{1)}$, P.I. Stoev ${ }^{1,2)}$, G.P. Kovtun ${ }^{1,2)}$, A.P. Shcherban ${ }^{1)}$, D.A. Solopikhin ${ }^{1)}$, \\ T.Yr. Rudycheva ${ }^{1)}$ \\ ${ }^{1)}$ National Scientific Center "Kharkov Institute of Physics and Technology" \\ 1, Akademicheskaya st., 61108, Kharkov, Ukraine, tel/fax 057-335-60-27 \\ E-mail: garin@kipt.kharkov.ua \\ ${ }^{2)}$ V.N. Karazin Kharkov National University \\ 61022, Kharkov, Svoboda square, 4, tel/fax 057-335-28-33 \\ Received April 12, 2017
}

The paper presents the results of a study for compression deformation of cadmium samples of different purities at room temperature. The analysis of hardening and recovery processes that influence the formation of the structure in the material is carried out. Conditions for starting work and features of dynamic recovery and dynamic recrystallization in samples of technical and distilled cadmium are considered, which result in softening of the material and grain growth in it. The differences in the course of these processes are determined depending on the purity of the initial samples of cadmium. On the basis of the analysis of changes in acoustic parameters (AE activity, amplitude distribution of signals in the AE spectrum, the contribution of signals of different amplitudes to the integrated spectrum of $\mathrm{AE}$ ), during deformation, we make assumptions about deformation mechanisms that occur at different stages of cadmium deformation. It is shown that the course of dynamic recovery processes during deformation is much more complicated than static recovery ones after deformation and subsequent annealing.

KEY WORDS: cadmium, deformation mechanisms, dynamic return, dynamic recrystallization, acoustic emission, amplitude distribution of AE signals

\section{ВИВЧЕННЯ ПЛАСТИЧНОЇ ДЕФОРМАЦІЇ КАДМІЮ \\ І.І. Папіров ${ }^{1)}$, П.І. Стоєв ${ }^{1,2)}$, Г.П. Ковтун ${ }^{1,2)}$, О.П. Щербань $^{1)}$, Д.О. Солопіхін ${ }^{1)}$, Т.Ю. Рудичева ${ }^{1)}$ \\ ${ }^{1)}$ Національний Науковий центр «Харківський фізико-технічний інститут» вул. Академічна 1, м. Харків 61108, Україна, тел/факс 057-335-60-27 \\ ${ }^{2)}$ Харківський національний університет імені В.Н. Каразіна \\ 61022, м. Харків, майдан Свободи, 4, тел/факс 057-335-28-33}

У роботі наведені результати дослідження зразків кадмію, які були деформовані стиском при кімнатній температурі. Проведено аналіз зміцнюючих і відновлюючих процесів, які впливають на формування структури в матеріалі. Розглянуто умови початку роботи і особливості динамічного відновлення і динамічної рекристалізації в зразках технічного та дистильованого кадмію, результатом яких є знеміцнення матеріалу і зростання в ньому зерна. Встановлено відмінності протікання цих процесів залежно від чистоти вихідних зразків кадмію. На основі аналізу зміни у поведінці акустичних параметрів (активності АЕ, амплітудного розподілу сигналів в спектрі АЕ, вкладу сигналів різної амплітуди в інтегральний спектр АЕ) при деформації матеріалу зроблені припущення про механізми деформації, які протікають на різних стадіях деформування кадмію. Показано, що перебіг динамічних зворотних процесів при деформації проходять значно складніше, ніж статичні після деформування і наступних відпалів.

КЛЮЧОВІ СЛОВА: кадмій, механізми деформації, динамічне відновлення, динамічна рекристалізація, акустична емісія, амплітудний розподіл сигналів $\mathrm{AE}$

\section{ИЗУЧЕНИЕ ПЛАСТИЧЕСКОЙ ДЕФОРМАЦИИ КАДМИЯ}

\author{
И.И. Папиров ${ }^{1)}$, П.И. Стоев ${ }^{1,2)}$, Г.П. Ковтун ${ }^{1,2)}$, А.П. Щербань ${ }^{1)}$, Д.А. Солопихин ${ }^{1}$, Т.Ю. Рудычева ${ }^{1)}$ \\ ${ }^{1)}$ Национальный Научный Центр “Харьковский физико-технический институт \\ ул. Академическая 1, г. Харьков, 61108, Украина, тел/факс 057-335-60-27 \\ ${ }^{2)}$ Харьковский национальный университет имени В.Н. Каразина, 61022 \\ м. Харьков, пл. Свободы, 4, тел/факс 057-335-28-33
}

В работе приведены результаты исследования деформирования сжатием образцов кадмия различной чистоты при комнатной температуре. Проведен анализ упрочняющих и восстанавливающих процессов, которые влияют на формирование структуры в материале. Рассмотрены условия начала работы и особенности динамического возврата и динамической рекристаллизации в образцах технического и дистиллированного кадмия, результатом которых является разупрочнение материала и рост зерна в нем. Установлены различия протекания этих процессов в зависимости от чистоты исходных образцов кадмия. На основе анализа изменения акустических параметров (активности АЭ, амплитудного распределения сигналов в спектре АЭ, вклада сигналов различной амплитуды в интегральный спектр АЭ) сделаны предположения о механизмах деформации, которые протекают на различных стадиях деформирования кадмия. Показано, что протекание динамических возвратных процессов при деформировании проходят значительно сложней, чем статические после деформирования и последующих отжигов.

КЛЮЧЕВЫЕ СЛОВА: кадмий, механизмы деформации, динамический возврат, динамическая рекристаллизация, акустическая эмиссия, амплитудное распределение сигналов АЭ

Кадмий широко применяется в различных отраслях промышленности. Основная часть промышленного потребления кадмия приходится на кадмиевые защитные покрытия, предохраняющие металлы от коррозии, и (C) Papirov I.I., Stoev P.I., Kovtun G.P., Shcherban A.P., Solopikhin D.A., Rudycheva T.Yr., 2017 
на производство сплавов. Сплавы кадмия обладают достаточной пластичностью и хорошо поддаются механической обработке. Сплавы кадмия с небольшими добавками никеля, меди и серебра используют для изготовления подшипников мощных судовых, авиационных и автомобильных двигателей и аккумуляторов. Кроме того кадмий используется в ювелирном деле и стоматологии.

Благодаря высокому сечению захвата тепловых нейтронов, чистый кадмий используется для изготовления регулирующих и аварийных стержней ядерных реакторов на медленных нейтронах.

Несмотря на достаточно широкое использование кадмия особенности процессов его пластической деформации и рекристаллизации изучены недостаточно. Вследствие низкой температуры его плавления $\left(320,9^{\circ} \mathrm{C}\right)$, они иметь ряд интересных особенностей. В справочной литературе приведены механические характеристики кадмия (предел прочности при растяжении $45-64$ мН/м², относительное удлинение $15-20 \%$, твердость по Бринеллю $160 \mathrm{MH} / \mathrm{M}^{2}$. Данные по изучению влияния структурных факторов на свойства кадмия практически отсутствуют.

Для исследования кинетических закономерностей процессов пластической деформации и разрушения конструкционных материалов широко используют структурно чувствительный метод акустической эмиссии. Поэтому целью данной работы является изучение особенностей пластической деформации и акустических параметров в процессе деформации кадмия различной чистоты.

\section{МАТЕРИАЛ И МЕТОДИКА ИССЛЕДОВАНИЯ}

Материалом для исследований служил кадмий марки ЧДА и кадмий высокой чистоты (> 99,9994 мас.\%), полученный комплексным методом рафинирования, включающим прогрев, фильтрацию и дистилляцию в вакууме [1]. Состав исследованных сортов кадмия приведен в таблице.

Таблица

Примесный состав исходного кадмия и кадмия высокой чистоты, полученного комплексным методом рафинирования

\begin{tabular}{|c|c|c|}
\hline \multirow{2}{*}{ Элемент } & \multicolumn{2}{|c|}{ Содержание примесей, $\mathrm{ppm}^{*}$} \\
\cline { 2 - 3 } & $\begin{array}{c}\text { исходный } \\
\text { кадмий }\end{array}$ & $\begin{array}{c}\text { рафинированный } \\
\text { кадмий }\end{array}$ \\
\hline $\mathrm{Mg}$ & 30 & $<0,5$ \\
\hline $\mathrm{Al}$ & 1,5 & $<0,1$ \\
\hline $\mathrm{K}$ & 8,3 & $<0,7$ \\
\hline $\mathrm{Ca}$ & 14 & $<0,5$ \\
\hline $\mathrm{Cr}$ & 0,2 & 0,1 \\
\hline $\mathrm{Mn}$ & 0,2 & 0,1 \\
\hline $\mathrm{Fe}$ & 4 & 0,2 \\
\hline $\mathrm{Co}$ & 0,3 & $<0,03$ \\
\hline $\mathrm{Ni}$ & 30 & 0,3 \\
\hline $\mathrm{Cu}$ & 4,7 & 0,3 \\
\hline $\mathrm{Zn}$ & 12 & $<0,5$ \\
\hline $\mathrm{Ag}$ & 0,2 & 0,03 \\
\hline $\mathrm{Pb}$ & 100 & 3 \\
\hline $\mathrm{Cd} \%$ & $\sim 99,98$ & $>99,9994$ \\
\hline
\end{tabular}

*содержание примесей в кадмии определяли методом лазерной масс-спектрометрии.

Из технического и дистиллированного кадмия получали слитки диаметром 12 мм, которые подвергали волочению при комнатной температуре $(\mathrm{T}=300 \mathrm{~K})$ до диаметра 5 мм. Из полученной проволоки с помощью электроэрозионной резки вырезали образцы длиной 6 мм и подвергали их химическому травлению.

Деформирование сжатием образцов кадмия проводили на универсальной испытательной машине 1958 -У10 при комнатной температуре со скоростью деформации 5,5·10-4 $\mathrm{c}^{-1}$. Синхронно с механическими характеристиками с помощью акустического комплекса M400 регистрировали параметры акустической эмиссии (активность, общую сумму импульсов, среднюю амплитуду и др.), анализ которых позволял определять, особенности деформации материала на разных стадиях деформации, а амплитудное распределение акустических сигналов АЭ позволяло оценить энергетику деформации. В качестве датчика-регистратора АЭ использовали пьезокерамический преобразователь из керамики ЦТС-19 с резонансной частотой 180 кГц. Датчик крепили на обратной стороне испытательного стола соосно с образцом. Сбор, обработку и анализ результатов, включавших информацию об акустической эмиссии и параметрах деформирования, проводили с помощью ЭВМ и специально разработанных программ обработки данных. Методика регистрации сигналов АЭ и обработки полученных результатов приведена в работе [2]. 


\section{ЭКСПЕРИМЕНТАЛЬНЫЕ РЕЗУЛЬТАТЫ}

На рис.1 приведены кривые сжатия в координатах «напряжение-деформация» образцов технической чистоты (кривая 1) и дистиллированного (кривая 3) кадмия.

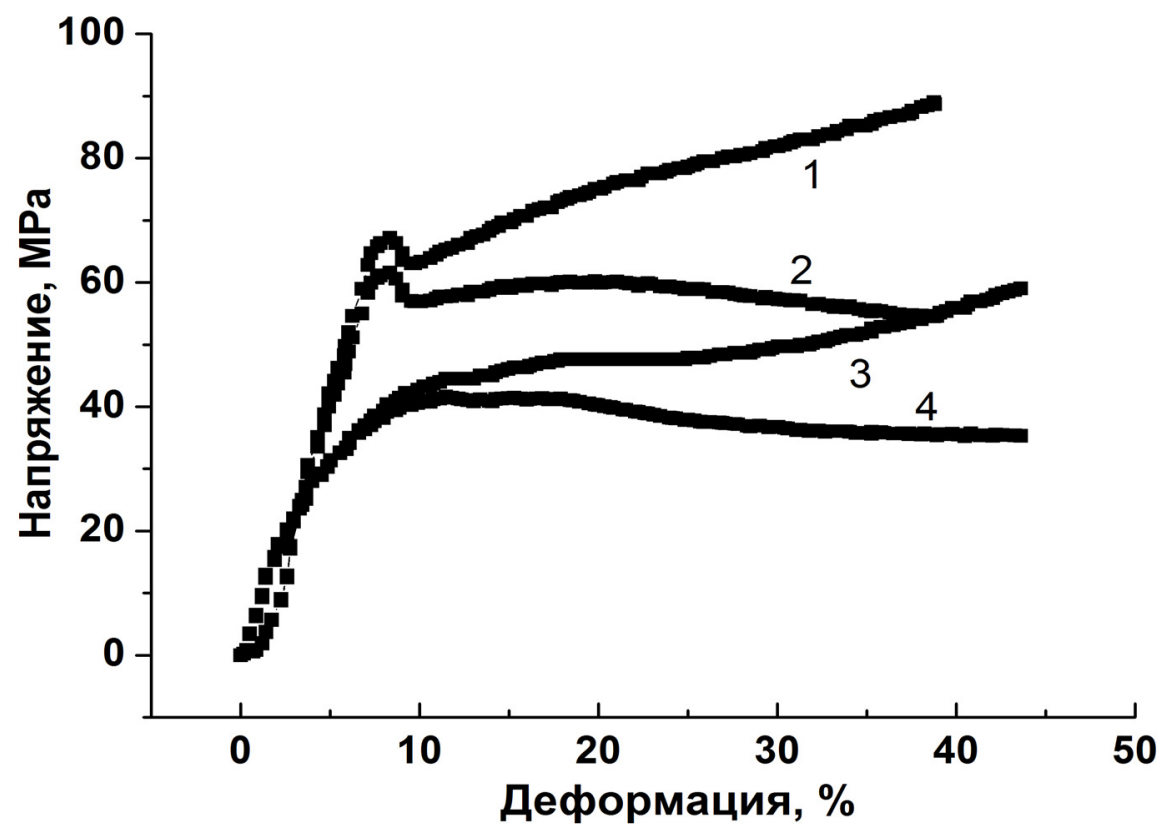

Рис. 1. Кривые деформирования в координатах «напряжение-деформация» образцов технической чистоты (кривая 1) и дистиллированного (кривая 3) кадмия и кривые «истинное напряжение-деформация» (кривые 2 и 4 соответственно)

Обращаем внимание на следующие особенности полученных результатов:

- предел текучести $\left(\sigma_{\mathrm{T}}^{\text {дист }}=27,4 \mathrm{MПа,} \sigma_{\mathrm{T}}^{\text {техн }}=66,0\right.$ Мпа) и напряжение для достижения сравнимой деформации у дистиллированного материала существенно ниже, чем у технического (например, для деформации $\sim 30 \% \sigma^{\text {дист }}=54,3 \mathrm{MПа}$, а $\sigma^{\text {техн }}=85,4 \mathrm{MПа),} \mathrm{то} \mathrm{есть} \mathrm{в} \mathrm{течение} \mathrm{процесса} \mathrm{сжатия} \mathrm{деформирование}$ технического кадмия происходит при более высоких напряжениях. Это вызвано большим количеством примесей в техническом кадмии, которые затрудняют пластическое течение материала и меньшим размером зерна у исходных образцов по сравнению с дистиллированным кадмием (22 мкм и 44 мкм соответственно).

- на кривой деформирования технического материала в области начала пластической деформации четко проявляется зуб текучести;

- кривые деформации свидетельствуют о слабой интенсивности нарастания упрочнения в образцах кадмия и имеют вид подобный кривым деформации при сжатии таких металлов, как цинк, свинец и др. (но радикальным образом отличаются от кривых деформации для аналогичных по геометрии образцов титана ВТ10 и других металлов, которые мы предварительно испытывали на стадии отработки методики деформирования сжатием).

Поскольку в процессе испытания на сжатие существенно изменялось сечение образцов, были расчитаны истинные напряжения, которые действуют на образцы и построены кривые деформации в координатах «истинное напряжение-деформация» (см. рис. 1, кривые 2 и 4).

На этих кривых (кривые 2 и 4) хорошо видно, что в процессе нагружения материала после достижения определенной деформации (12\% для технического и 7\% для дистиллированного кадмия) наблюдается падение истинного напряжения течения, то есть материал начинает разупрочняться. В связи с малыми скоростями деформации этот эффект нельзя связывать с нагревом образцов и поэтому этот уникальный эффект деформационного разупрочнения был подробно изучен авторами в настоящей работе.

На рис. 2 приведены структуры образцов кадмия различной чистоты в исходном состоянии и после деформации сжатием при комнатной температуре.

Анализ микроструктур образцов технического и дистиллированного кадмия в исходном состоянии и после деформирования (рис. 2) показал, что в процессе деформирования образцов различной чистоты происходит не измельчение (как обычно), а рост зерен (динамика роста и конечный размер зерен зависит от чистоты материала).

Полученные результаты показывают, что деформация образцов кадмия различной чистоты при комнатной температуре со скоростью деформации $5,5 \cdot 10^{-4} \mathrm{c}^{-1}$ сопровождается их разупрочнением и увеличением размера зерен. 


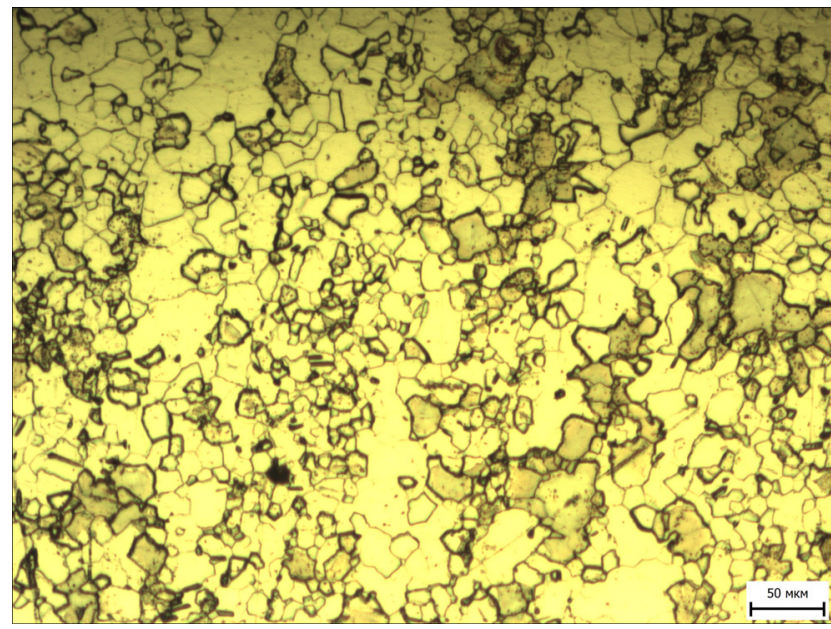

a
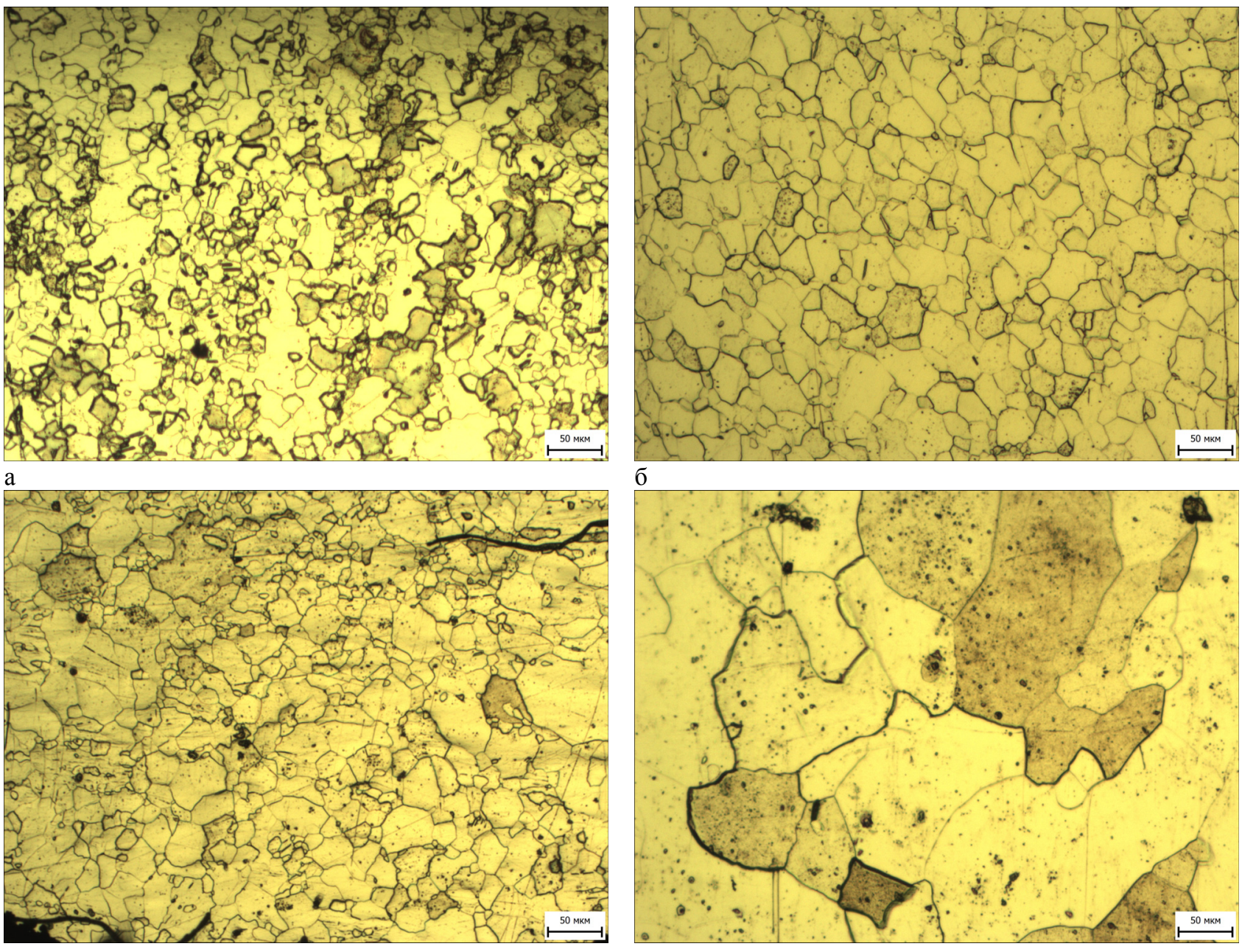

B

Рис. 2. Структура деформированного технического (a, б) и дистиллированного кадмия (в, г) в исходном состоянии (a, в) и после деформации при $20^{\circ} \mathrm{C}(б$, в)

Таким образом, наряду с ранее известным явлением динамической рекристаллизации при деформации металлов обнаружен эффект роста зерен, связанный с трансформацией энергии деформации в энергию роста зерен в чистых металлах с низкой температурой рекристаллизации. Подобное явление ранее наблюдалось лишь при высокой температуре [3-5].

\section{ОБСУЖДЕНИЕ ЭКСПЕРИМЕНТАЛЬНЫХ РЕЗУЛЬТАТОВ}

Для анализа полученных экспериментальных результатов проанализируем имеющиеся в литературе данные об особенностях изменения структуры в процессе холодной деформации металлов.

\section{Стадия деформационного упрочнения}

Одним из основных механизмов пластической деформации металлов является внутризеренное скольжение, ведущее к увеличению плотности дислокаций леса и приводящее к упрочнению материала [6-9]. Если у отожженного поликристаллического металла плотность дислокаций обычно равна $10^{6}-10^{8} \mathrm{~cm}^{-2}$, то при деформации на несколько процентов она возрастает до $10^{8}-10^{9}$, а при сильной деформации до $10^{11}-10^{12} \mathrm{~cm}^{-2}$. Следовательно, плотность дислокации при холодной деформации в материале может возрасти на пять-шесть порядков [7].

С ростом нагрузки деформация зерен сопровождается изгибами и поворотами плоскостей скольжения. Зерна вытягиваются в направлении пластического течения. Концентрация дефектов (дислокаций, вакансий, межузельних атомов) внутри зерен возрастает. Дефекты затрудняют движение дислокаций: сопротивление деформированию растет. При степенях деформации примерно 5 - $10 \%$ у многих металлов и сплавов начинают формироваться ячеистая структура: сплетения дислокаций связываются между собой, образуя объемные границы областей, внутри которых плотность дислокации сравнительно невелика. Образующиеся при деформации ячейки обычно имеют размер около 1 микрона и на порядок меньше толщину границ (десятые доли микрона). Накопление дислокаций и образование ячеистых структур приводят к существенному затруднению процесса деформирования и к упрочнению металла в ходе пластической деформации [9]. Иными 
словами, деформационная обработка приводит металл в неравновесное состояние с повышенной свободной энергией.

Состояние наклепанного металла является термодинамически неустойчивым, поэтому при механической или термической активации система стремится перейти в более стабильное состояние [10].

Различают следующие стадии восстановительных процессов, устраняющих дефекты кристаллической структуры, вносимых деформацией:

- возврат (отдых, полигонизация);

- рекристаллизация (первичная, собирательная, вторичная) [3,4,11-13].

\section{Динамический возврат}

Первым включается самый низкотемпературный (низкоэнергетический) разупрочняющий процесс динамический отдых. У легкоплавких металлов при комнатной температуре подвижность атомов достаточна, чтобы обеспечить активное развитие восстановительных процессов. Начинают работать различные механизмы уменьшения накопленной при деформации энергии. Эти процессы направлены на уменьшение общего количества дефектов кристаллической решетки и перераспределению их в кристаллитах с образованием более равновесных конфигураций. Межузельные атомы аннигилируют на краевых дислокациях и при встрече с вакансиями. Вакансии мигрируют к дислокациям и границам зерен и здесь аннигилируют. Идет локальная перегруппировка дислокаций и взаимная аннигиляция дислокаций разного знака.

Особенностью этого процесса, который протекает при сравнительно низких гомологических температурах $\left(0,2-0,25 \mathrm{~T}_{\text {пл }}\right)$ является тот факт, что возврат протекает без образования и миграции субграниц внутри зерен.

У материала с большим количеством примесей затруднено перемещение вакансий, поэтому динамика возврата есколько ослабевает.

Индикатором работы динамического отдыха при увеличении величины деформации является незначительное изменение (падение) наклона кривой «напряжение-деформация», то есть происходит снижение интенсивности упрочнения материала.

С повышением степени деформации ячеистая структура становится более ярко выраженной. Границы ячеек становятся более узкими, а из объемных они стремятся превратиться в плоские. Ячейки полностью оконтуриваются границами, и внутри ячеек остается совсем мало дислокаций. Начинают создаваться субзерна (хорошо оформленные ячейки с плоскими стенками) и субзеренная структура. Средняя плотность дислокаций при увеличении степени деформации возрастает в результате роста их плотности в скоплениях на границах, а не внутри ячеек. Соседние ячейки и субзерна разориентированы на углы, находящиеся в интервале от нескольких секунд до нескольких градусов.

При деформировании материала процессы образования из ячеистой структуры субзеренной структуры являются свидетельством того, что в материале проходит динамическая полигонизация, которая существенно уменьшает деформационное упрочнение. На стадии динамической полигонизации проходит перестройка дислокационной структуры, которая сформировалась при деформации. Перестройка происходит путем перераспределения дислокаций поперечным скольжением и диффузионным переползанием с выстраиванием дислокаций в стенки (образование плоских дислокационных границ), сопровождаясь их частичной аннигиляцией и образованием субзерен внутри кристаллитов, свободных от дислокаций и отделенных друг от друга дислокационными малоугловыми границами. Субзерна, которые сформированы в процессе полигонизации, при определенной температуре стремятся укрупняться. Экспериментально установлены два механизма этого укрупнения - миграция субграниц и коалесценция субзерен.

При слиянии субграниц и перемещения тройного стыка два субзерна растут за счет третьего, а разориентация субзерен около образующейся границы увеличивается. При коалесценции субзерен граница между субзернами полностью исчезает, так как дислокации уходят из нее в субграницы, окружающие эти субзерна.

Рост субзерен при полигонизации также приводит к увеличению углов разориентировки соседних субзерен. Однако, на стадии полигонизации, границы все время остаются малоугловыми, а угол разориентировки соседних субзерен не превышает $\sim 10-15^{\circ}$ (чаще соседние зерна разориентированы на угол не более $1-2^{\circ}$ ) [11].

При полигонизации свободная энергия кристалла должна снизиться, потому что в результате перестройки уменьшается плотность дислокаций, а остающиеся стремятся образовать устойчивые конфигурации, отличающиеся минимальной энергией, например в виде стенок или сеток, являющихся малоугловыми границами.

Таким образом, в процессе деформации деформационное упрочнение из-за повышения плотности дислокаций и увеличения эффективности их торможения будет конкурировать с разупрочнением из-за снижения плотности дислокаций и совершенствования дислокационной структуры в результате динамического возврата. При определенной степени деформации в процессе динамического возврата число вновь образовавшихся дислокаций будет меньше, чем число аннигилирующих, поэтому на кривой деформации будет 
наблюдаться деформационное разупрочнение [9].

Кроме того, при протекании восстановительного разупрочняющего процесса динамического возврата, в процессе деформирования создаются структурные и энергетические условия необходимые для зарождения центров кристаллизации и протекания процесса динамической рекристаллизации.

\section{Динамическая рекристаллизация}

Начиная с определенной степени деформации, у металла происходит существенное изменение структуры и может начинаться процесс динамической рекристаллизации. При этом происходит наиболее радикальное уменьшение объемной энергии деформированных кристаллов за счет уменьшения числа дефектов структуры, внесенных деформацией [12].

Движущей силой первичной стадии динамической рекристаллизации является энергия, аккумулированная в наклепанном металле, связанная в основном с дислокациями и точечными дефектами. Уменьшение плотности дислокаций при переходе системы в устойчивое состояние с неискаженной кристаллической решеткой приводит к высвобождению основной доли этой накопленной энергии. Динамическая рекристаллизация в металле при деформации возникают при достижении критической плотности дислокаций, которой соответствует так называемая критическая степень деформации.

Начало динамической рекристаллизации определяется совместным действием нескольких факторов, прежде всего степенью деформации и температурой, которые соответственно задают критическую плотность дислокаций и диффузионную активность материала.

На начальной стадии рекристаллизации идет образование центров кристаллизации и рост новых равновесных зерен с неискаженной кристаллической решеткой. Главным в механизме зарождения рекристаллизованных зерен является формирование участка с высоким структурным совершенством, окруженного высокоугловыми границами и отделенным этими границами от матрицы. Новые зерна возникают на границах старых зерен и блоков, где решетка была наиболее искажена. Чем больше степень пластической деформации, тем больше возникает зародышей. Зародыши растут путем диффузии атомов от деформированных участков. Когда количество центров станет достаточно много, то из-за пониженной плотности дислокаций внутри этих рекристаллизованных зерен образуется участок разупрочнения. При продолжении деформации этот процесса охватывает весь объем образца.

Количество новых зерен постепенно увеличивается и в структуре не остается старых деформированных зерен. Пока рекристаллизованные зерна с пониженной прочностью занимают небольшую часть объема материала, еще продолжается рост напряжения течения, но с заметным уменьшением коэффициента упрочнения. С увеличением суммарного объема рекристаллизованных участков разупрочнение перекрывает деформационное упрочнение, и напряжение течения начнет уменьшаться. При этом наряду с вытянутыми деформированными зернами появляются более или менее равноосные рекристаллизованные зерна. Площадь материала, занятая новыми зернами, возрастает, а старые деформированные зерна исчезают. Новые зерна имеют более совершенное внутреннее строение, с пониженной плотностью дислокаций.

Размер зерна к завершению начальной стадии динамической рекристаллизации зависит от соотношения скорости зарождения центров кристаллизации и линейной скорости их роста.

По окончанию начального этапа динамической рекристаллизации, когда исчезают старые деформированные зерна, структура остается нестабильной из-за большой свободной энергии сильно развитой поверхности границ рекристаллизованных зерен и неуравновешенности поверхностного натяжения на этих границах.

Последующим этапом динамической рекристаллизации являются процессы роста одних рекристаллизованных зерен за счет соседних рекристаллизованных зерен путем миграции высокоугловых границ. Термодинамическим стимулом этой стадии динамической рекристаллизации является свободная энергия границ зерен, а обязательным условием ее развития - неуравновешенность поверхностного натяжения, стремящегося выпрямить искривленные границы и сделать равновесную конфигурацию границ в тройных стыках.

Рекристаллизованные зерна растут путем быстрой миграции их границ в сторону деформированной матрицы. Движущей силой такой миграции является разность в упругой энергии кристаллов по обе стороны от границы из-за разной плотности дислокаций. Движущая высокоугловая граница «выметает» на своем пути дефекты решетки деформированной матрицы, увеличивая объем с более совершенной структурой, с резко меньшей плотностью дислокаций.

Пока рекристаллизованные зерна с пониженной прочностью занимают небольшую часть объема материала, еще продолжается рост напряжения течения. С увеличением суммарного объема рекристаллизованных участков разупрочнение перекрывает деформационное упрочнение, и напряжение течения падает. На кривых «напряжение-деформация» динамический возврат проявляется в снижении коэффициента упрочнения.

При динамической рекристаллизации появившиеся рекристаллизованные зерна с низкой плотностью дислокаций во время своего роста постепенно наклепываются из-за продолжающейся деформации - в них 
повышается плотность дислокаций. Участки, рекристаллизовавшиеся в первую очередь, начинают наклепываться раньше и в них быстрее достигаются критическая плотность дислокаций, необходимая для зарождения новых рекристаллизованных зерен, которые затем наклепываются, и т.д. Наклеп рекристаллизованных зерен уменьшает разность в плотности дислокаций по обе стороны от мигрирующей границы, а так как эта разность является движущей силой миграции, то скорость роста рекристализованных зерен уменьшается. Чем выше температура и ниже скорость деформации, тем крупнее и совершеннее рекристаллизованные зерна.

Многократно чередующие циклы динамической рекристаллизации и наклепа рекристаллизованных зерен соответствует установившейся стадии с неизменным средним размером зерна.

Исключительно сильно на размер зерна в завершающей стадии начальной стадии динамической рекристаллизации влияет степень деформации. В зернах, где деформация достигла критической (обычно от 5 до 15\%) величины, вырастает крупное зерно.

В определенный момент деформации наступает динамическое равновесие между количеством новых дислокаций и исчезающих в результате непрерывно продолжающей динамической рекристаллизацией (установившаяся стадия деформации). Обычно переход к установившейся стадии происходит после истинной деформации на 10 - 50\% и зависит от скорости деформирования и температуры [4].

На кривых деформации динамическая рекристаллизация материала проявляется в падении напряжения течения и после определенной деформации переходом к установившейся стадии деформации. Таким образом, в процессе деформирования материала, работающие параллельно упрочняющие и динамические разупрочняющие процессы, приводят к разупрочнению материала и росту зерна в нем. Естественно, указанные процессы во многом определяются температурой деформации, а точнее - ее соотношением с температурой плавления исследуемого металла. Это связано с тем, насколько развита диффузионная подвижность при температуре испытаний и с влиянием на диффузионную подвижность уровня напряжений.

Рассмотрим более подробно полученные в работе результаты.

При анализе особенностей изменения структуры кадмия в процессе деформирования следует учитывать следующее. Кадмий относится к легкоплавким металлам и поэтому все установленные температурные области для многих металлов (гомологические температуры в частях от $\mathrm{T}_{\text {пл}}$ ) начала прохождения процессов статического возврата и рекристаллизации оказываются значительно ниже комнатной температуры, при которой авторы проводили испытания образцов кадмия.

Иными словами, в нашем случае термическая активация восстановительных процессов энергетически обеспечена на всем этапе деформирования кадмия при комнатной температуре, а начало работы разупрочняющих процессов определяется только уровнем деформации и величиной скорости деформирования.

В процессе испытания образцов кадмия на кривой «нагрузка - истинная деформация» после прямолинейного участка, которая соответствует стадии упругой деформации, наблюдаются криволинейные участки, которые отражают особенности протекания пластической деформации. Условно, эти участки кривой деформации разделяют на три стадии: деформационного упрочнения, разупрочнения и установившегося течения [8,9].

Из рис. 1 (кривые 2 и 4) видно, что в процессе нагружения материала после достижения определенной деформации (12\% для технического и 7\% дистиллированного кадмия) наблюдается падение истинного напряжения течения, то есть материал разупрочняется.

Проанализируем характер и причины изменений кривых деформации при сжатии образцов кадмия при комнатной температуре. В начальный момент сжатия образцов кадмия на кривой деформации регистрируется упругая деформация. В области предела текучести наблюдается существенное различие в поведение кривых деформации образцов кадмия различной чистоты. У образцов дистиллированного кадмия в области предела текучести кривая деформации имеет плавный переход к пластическому течению. На кривой деформации технического кадмия хорошо просматривается зуб текучести, который отсутствует на кривой деформации дистиллированных образцов кадмия (рис. 1, кривые 1 и 3). Наличие зуба текучести у технического кадмия обусловлено скоплением атомов примесей вблизи дислокаций и блокированием их перемещения. Некоторое повышение напряжения, наблюдаемое на кривой деформации, связано с тем, что отрыв дислокаций от скоплений атомов примесей требует более высоких напряжений, чем последующее их движение в металле $[6,8,14]$.

Из рис. 1 видно, что при напряжениях выше предела текучести в образцах кадмия начинается пластическое течение и наблюдается присущее этому процессу деформационное упрочнение [9,14]. Сравнение кривых 1 с 2 и 3 с 4 рис. 1 показывает, что ход кривых деформации не только отличается коэффициентом упрочнения, но и характером его изменения. На машинных диаграммах (в координатах «нагрузкадеформация») наблюдается заметный подъем кривой деформации, который вызван ростом поперечного сечения образцов, происходящим при деформировании. Сильное влияние увеличения сечения образца скрывает очень важную особенность деформирования, которая хорошо видна на расчетных истинных кривых деформирования: малую величину коэффициента упрочнения у образцов кадмия, а после небольшой их деформации тенденцию к постоянному его уменьшению. По нашему мнению, это связано с началом работы 
восстановительных динамических процессов - на начальной стадии пластического течения этим процессом, вероятно, является динамический отдых. Это самый низкотемпературный (малоэнергетический) из восстановительных процессов.

С увеличением величины деформации образцов кадмия коэффициент упрочнения монотонно снижается, вероятно, к процессу динамического отдыха подключается процесс динамической полигонизации. Как было показано выше, работа этих процессов приводит к снижению концентрации дефектов и плотности дислокаций (концентрация которых в результате деформирования увеличивается на 5-6 порядков), формированию субзеренной структуры: областей кристалла, разделенных малоугловыми границами и свободных от дислокаций. Помимо движения одиночных дислокаций, динамическая полигонизация включает на стадии формирования субграниц миграцию дислокационных групп и на стадии роста субзерен - миграцию малоугловых дислокационных границ.

Таким образом, при дальнейшей деформации образца, параллельно с процессом упрочнения начинают работать два восстанавливающих процесса динамического возврата (динамический отдых и полигонизация), которые снижают упрочнение материала.

Дальнейшая деформация образцов кадмия создает условия для роста и увеличения угла разориентации субзерен. Можно утверждать, что при деформации около $10 \%$ к процессу подключается начальная стадия динамической рекристаллизации. Активность восстановительных процессов существенно растет и заметно меняет характер кривой деформации. При деформациях порядка $15 \%$ включается следующая стадия динамической рекристаллизации: возникают зародыши новых зерен и начинается их рост.

Новые зерна имеют более совершенную структуру и отсутствие дислокаций в теле зерен. То есть в материале интенсивно создаются зоны разупрочнения, которые быстро распространяются на весь материал. Активность восстановительных процессов существенно растет и заметно меняет характер кривой деформации образцов кадмия. Дальнейший ход кривой деформации будет определяться параллельной работой процессов упрочнения и восстанавливающими разупрочняющими процессами.

В отличие от статических процессов восстановления свойств материала после деформационной обработки путем высокотемпературных отжигов со строго определенной стадийностью, динамические процессы восстановления, которые идут непосредственно вместе с процессами деформирования и активируются определенным уровнем деформации (и, соответственно - диффузионной подвижности) являются более сложными.

Следует учитывать, что статические процессы активируются температурой и зависят от величины температуры и времени обработки, а динамические процессы активируются деформацией и зависят от величины деформации и от скорости деформирования.

Различия протекания статических и динамических восстановительных процессов приводит к особенностям формирования структуры материала. Так при динамической рекристаллизации создается неоднородная структура по объему металла и внутри отдельных зерен, связанная с тем, что одни участки материала только что рекристаллизовались, а другие ранее рекристаллизованные участки начинают упрочняться, а в третьих идут процессы динамического возврата. Многократно чередующие циклы динамической рекристаллизации и наклепа рекристаллизованных зерен в зависимости от преобладания одного из этих процессов приводит либо к снижению коэффициента упрочнения и разупрочнению, либо к его постоянству, что приводит к установившейся стадии деформации.

Стадия установившегося течения просматривается на кривой деформации дистиллированного кадмия при деформировании на 30 - 32\% (кривая 4, рис. 1). У кадмия технической чистоты этой стадии нет, вероятно, из-за того, что при деформировании этого сорта образцов кадмия мы не достигли величины необходимой истинной деформации, при которой происходит переход к стадии установившегося течения (считается, что переход к установившейся стадии происходит после деформации материала на 30-50\%). Возможно, примеси существенно влияют на деформационный порог начала динамического равновесия новых и исчезающих дислокаций [4].

\section{Исследование акустической эмиссии}

Для более глубокого понимания процессов, которые протекают в образцах кадмия при деформировании, синхронно с механическими характеристиками регистрировали параметры акустической эмиссии.

На рис. 3 приведены совмещенные зависимости активности АЭ (кривая 2) с кривой деформации (кривая 1) для технического и дистиллированного кадмия от уменьшения высоты образца при сжатии.

Из рис. 3 видно, что акустическая эмиссия (АЭ) начинает регистрироваться уже на стадии упругой деформации. Этот факт мы неоднократно наблюдали при испытаниях различных конструкционных материалов (Be, $\mathrm{Zr}$, Ті и др.) и он связан с регистрацией процессов микропластической деформации материалов [2,15-17].

Следует обратить внимание на существенные отличия кривых зависимости активности АЭ от деформации для образцов технического и дистиллированного кадмия. У технического кадмия в области предела текучести наблюдается колебание активности АЭ от максимальных значений 500 до минимальных - 50 имп/с. Вероятно, это связано с особенностями отрыва дислокаций от примесей и повторным закреплением дислокаций примесями или с процессами сбросообразования, которые изучал Орован и в своей работе показал, что 
цилиндрические образцы кадмия при сжатии претерпевают локальные изломы в виде сбросов [18]. Полосы сброса образуются постепенно во время сжатия путем возрастающего поворота решетки, который может быть от единицы до нескольких десятков градусов.

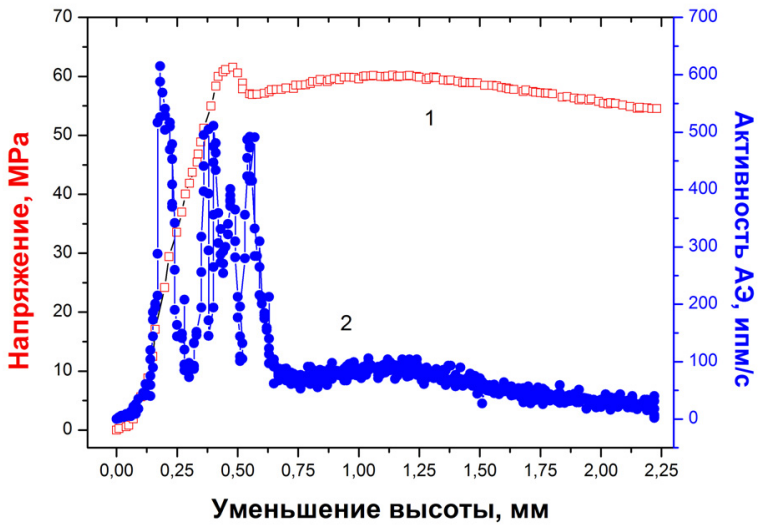

a

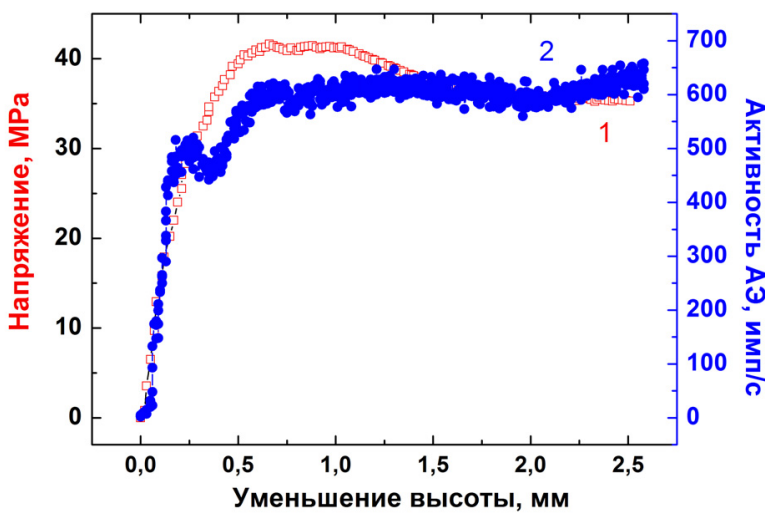

6

Рис. 3. Зависимость напряжения (кривая 1) и активности АЭ (кривая 2) у образцов технического (а) и дистиллированного кадмия (б) от уменьшения высоты образца при деформировании

Существенное увеличение активности АЭ обоих сортов кадмия в области предела текучести является характерным откликом параметров АЭ на начало пластического течения материала [19,20]. С увеличением деформации активность АЭ у образцов технического кадмия уменьшается и продолжает оставаться низкой в течение всего процесса деформирования. Такой вид зависимости активности АЭ характерен для многих конструкционных материалов деформированных растяжением и объясняется существенным исчерпанием числа движущихся дислокаций после прохождения предела текучести, где наблюдается максимум кривой активности АЭ [21,22]. А у дистиллированного кадмия активность после прохождения предела текучести не уменьшается, а продолжает оставаться на достаточно высоком уровне (600 имп/сек). Возможно, это связано с тем, что число источников сигналов не уменьшается за счет особенности протекания процессов, связанных с непрерывным возникновением при деформации новых подвижных дислокаций, которые поддерживают высокую активность акустического излучения.

Другое объяснение проявления такой зависимости активности при деформации дает в своей работе Р.О. Кайбышев при анализе роста зерен при динамической рекристаллизации магниевых сплавов [3]. Он установил, что во время пластического течения происходит плавное увеличение размера рекристаллизованных зерен. Причиной необычной зависимости размера рекристаллизованных зерен от степени деформации является образование двух разных структурных составляющих рекристаллизованных зерен. Их появление связано с различными механизмами деформации.

На ранних стадиях пластического течения действует двойникование. В результате активизируется «двойниковый» механизм динамической рекристаллизации, который приводит к образованию цепочек новых зерен на месте старых двойников. Формирующиеся рекристаллизованные зерна первой структурной компоненты близки по своему размеру к толщине двойников. Следует отметить, что "двойниковые" зерна образуются только на ранней стадии пластического течения. Формирование второй компоненты рекристаллизационного объема происходит благодаря действию "субзеренного" механизма динамической рекристаллизации, который связан со скольжением, накоплением и перераспределением, в объеме исходных зерен, дислокаций.

Еще более сильные различия проявились при анализе амплитудного распределения сигналов АЭ и зависимости вклада сигналов различной амплитуды в спектр АЭ. Гистограммы амплитудного распределения образцов технического и дистиллированного кадмия приведены на рис. 4. На рис. 5 показано изменение средней амплитуды импульса АЭ у образцов технического и дистиллированного кадмия в течение деформирования. Из рис. 4 видно, что в спектре распределения амплитуд у образцов технического кадмия преобладают сигналы низкой амплитуда, а у дистиллированного кадмия большинство сигналов в спектре АЭ высокоамплитудные. Обращаем внимание на то, что на стадии разупрочнения (столбик 2 гистограммы) вклад высокоамплитудных сигналов АЭ существенно больший по сравнению с распределением при деформации на стадии упрочнения (столбик 1). Из рис. 5 следует, что в течение всего процесса деформирования средняя амплитуда импульса АЭ у образцов дистиллированного кадмия в 2-4 раза была больше, чем амплитуда импульса АЭ у образцов технического материала.

Амплитуда сигналов АЭ, являясь энергетическим параметром, позволяет установить природу источника, генерирующего сигналы АЭ [19,21]. Поэтому, можно предположить, что деформация образцов технического кадмия реализуется низкоэнергетическими процессами, скорее всего дислокационным скольжением. А при 
деформировании дистиллированного кадмия источники АЭ высокоамплитудные. Также следует обратить внимание, что они начинают работать сразу же после начала деформирования. Из факторов, которые влияют на генерацию сигналов АЭ большой амплитуды, следует выделить: большой размер зерна и деформация двойникованием $[19,20]$.

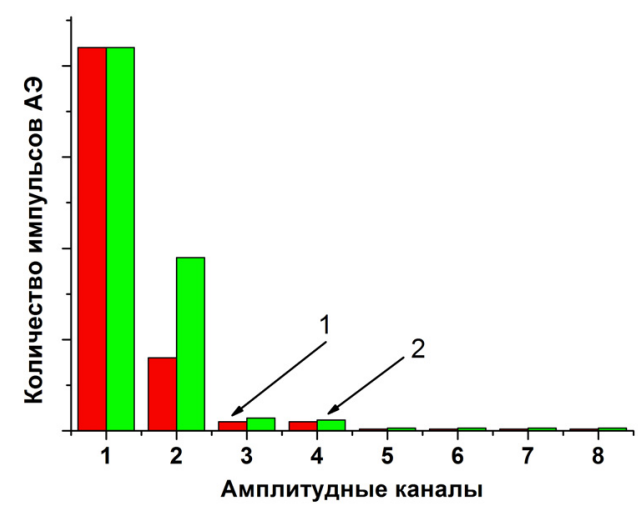

a

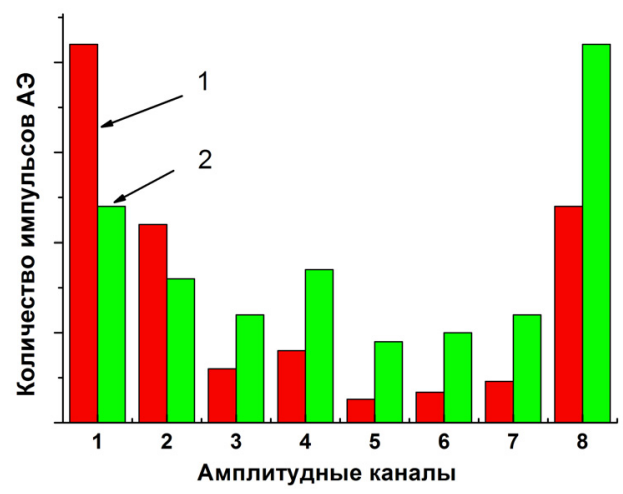

6

Рис. 4. Амплитудное распределение сигналов АЭ при деформировании образцов технического (а) и дистиллированного (б) кадмия: 1 - стадия упрочнения; 2 - стадия разупрочнения

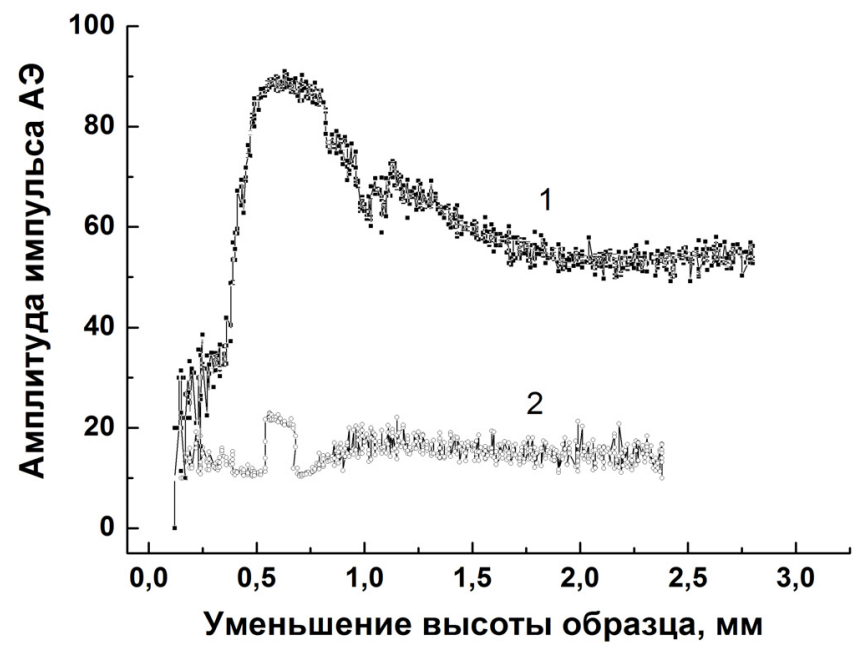

Рис. 5. Зависимость средней амплитуды импульса АЭ от уменьшения высоты образца дистиллированного (кривая 1) и технического (кривая 2) кадмия

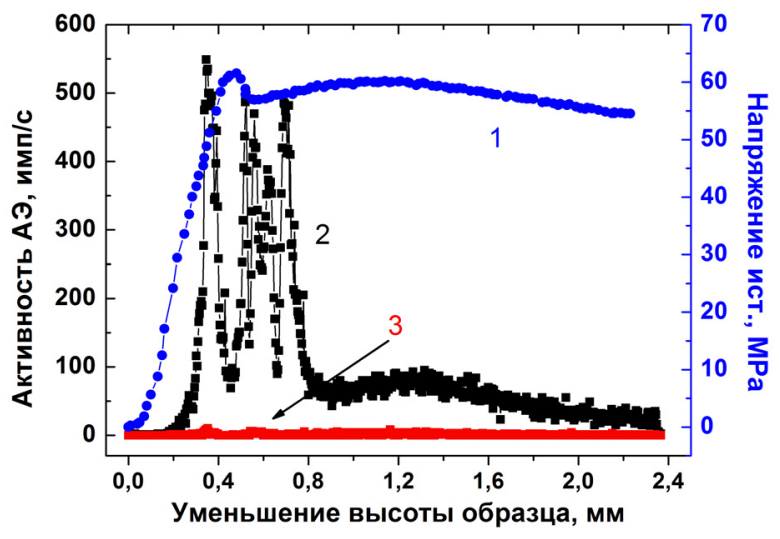

a

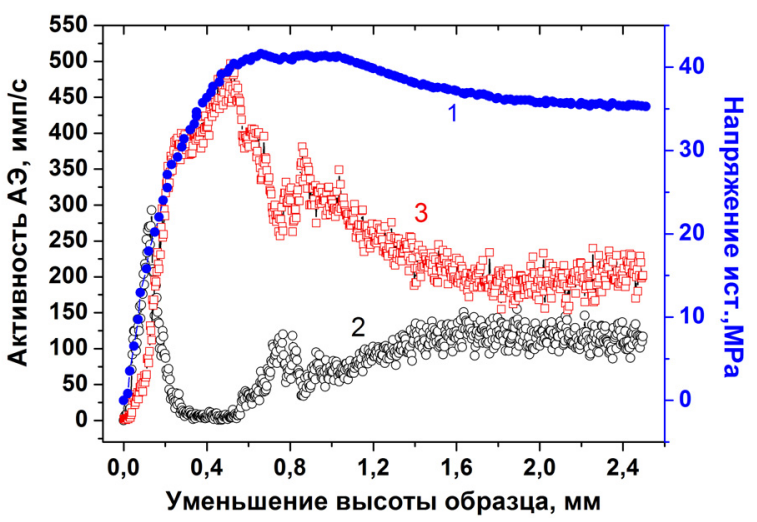

6

Рис.6. Совмещенный график кривой деформации (кривая 1) и зависимости изменения количества низко- (кривая 2) и высокоамплитудных (кривая 3) импульсов АЭ при деформировании образцов кадмия технической чистоты (а) и дистиллированного (б) 
Поэтому больший размер зерна у исходных образцов дистиллированного кадмия и его энергичный рост непосредственно в процессе деформирования может быть причиной генерации сигналов АЭ с большей амплитудой. Высокая амплитуда сигналов АЭ, которая регистрируется на начальной стадии деформирования дистиллированного кадмия, вероятно, связана с процессами двойникования, а при дальнейшем деформировании высокая амплитуда является следствием генерации высокоамплитудных сигналов АЭ материалами с более высоким размером исходного зерна и его ростом в процессе деформирования.

Ранее проведенные исследования при деформировании сжатием образцов магния позволили получить зависимость изменения активности с максимумом в области предела текучести и резким снижением активности АЭ при дальнейшем деформировании [15]. Напротив, при индентировании сферическим индентором образцов циркония и его сплава $\mathrm{Zr}-1 \% \mathrm{Nb}$ активность АЭ после предела текучести все время увеличивалась [2]. Поэтому вопрос о причинах резкого уменьшения активности генерации сигналов АЭ низкой амплитуды в образцах кадмия при напряжениях чуть выше предела текучести и отсутствие в спектре АЭ высокоамплитудных сигналов, а также высокая активность генерации исключительно высокоамплитудных сигналов АЭ в течение всего процесса деформирования образов дистиллированного кадмия остается открытым.

Значительные различия в характере изменения активности АЭ, амплитудном распределении и вкладе импульсов различной амплитуды в спектр сигналов АЭ при деформировании может свидетельствовать о сильном влиянии чистоты исходного металла на особенности пластической деформации. Сильное влияние химического состава материала и исходной микроструктуры на размер рекристаллизованных зерен и кинетику динамической рекристаллизации магниевых сплавов также отметил в своей работе Р.О. Кайбышев [3].

Существенные различия акустико-эмиссионных характеристик у образцов технического и дистиллированного кадмия создает впечатление, что мы испытываем два разных материала с различным механизмом деформации, а не один и тот же материал с небольшим отличием в количестве примесей. Для правильной интерпретации полученных результатов необходимы дальнейшие исследования с более широким привлечением методов структурного анализа.

\section{ЗАКЛЮЧЕНИЕ}

Полученные в работе результаты показывают, что деформация кадмия различной чистоты при комнатной температуре со скоростью $5,5 \cdot 10^{-4} \mathrm{c}^{-1}$ сопровождается их разупрочнением и ростом зерна. Формирование структуры в образцах кадмия, которые деформируют сжатием, происходит под влиянием деформационного упрочения и восстановительных (разупрочняющих) процессов: динамического возврата первого рода, динамической полигонизации и динамической рекристаллизации.

В отличие от закономерностей прохождения этих процессов после предварительной деформации и последующих отжигов, особенности работы этих процессов состоят в том, что они протекают непосредственно в процессе деформирования. После начала деформирования и прохождения стадии упругой деформации начинается пластическая деформация материала. После незначительной деформации материала (3 - 5\%) с небольшим интервалом последовательно включаются в работу отдых, потом полигонизация, затем первичная и собирательная рекристаллизация, которые продолжают совместно работать до окончания процесса деформации.

Обращаем внимание на то, что простые представления о статической рекристаллизации и возврате недостаточны для описания комплексного действия динамических процессов разупрочнения. Также достаточно сложно установить точные границы смены стадийности и определить вклад каждого процесса на различных участках деформирования.

Следует отметить, что на особенность прохождения динамических разупрочняющих процессов в процессе сжатия образцов кадмия сильное влияние оказывает чистота исходного металла. Это влияние проявляется как на характере изменения кривых деформации, так и на регистрируемых параметрах акустической эмиссии.

\section{СПИСОК ЛИТЕРАТУРЫ}

1. Bernabey R, Virich V.D., Grinev B.V., Danevich F.A., Kovtun G.P., Mokina V.M., Nagornaya L.L., Nagornyy S.S., Nisi S., Solopikhin D.A., Tretyak V.I., Shcherban'A.P. Poluchenie $\mathrm{Cd} \mathrm{i}{ }^{106} \mathrm{Cd}$ vysokoy chistoty dlya stsintillyatorov $\mathrm{CdWO}_{4} \mathrm{i}$ ${ }^{106} \mathrm{CdWO}_{4}$ [Production of high purity $\mathrm{Cd}$ and ${ }^{106} \mathrm{Cd}$ for $\mathrm{CdWO}_{4}$ and ${ }^{106} \mathrm{CdWO}_{4}$ scintillators] // Metallofizika i noveyshie tekhnologii [Metallophysics and the latest technologies].- 2008.- Tom 30 spets. vypusk. - P. 477-486. (in Russian)

2. Stoev P.I., Papirov I.I., Butenko I.N. Akusticheskaya emissiya chistogo tsirkoniya pri indentirovanii [Acoustic emission of pure zirconium under indentation] // Voprosy atomnoy nauki i tekhniki [Problems of atomic science and technology]. Seriya «Fizika radiatsionnykh povrezhdeniy i radiatsionnoe materialovedenie». - 2009.- No. 6. - P. 36-41. (in Russian)

3. Sitdikov O., Kaibyshev R. Dynamic recrystallization in pure magnesium //Institute for Metals Superplasticity Problems, Materials Transection.- 2001.- Vol. 42.- No.9.- P. 1928-1937.

4. Novikov I.I. Teoriya termicheskoy obrabotki metallov [Theory of heat treatment of metals]. - M: «Metallurgiya», 1986. - 480p. (in Russian)

5. Papirov I.I. i dr. Plasticheskaya i sverkhplasticheskaya deformatsiya berilliya [Plastic and superplastic deformation of beryllium]. - Izd. Dom MISiS, 2014. - 208p. (in Russian)

6. Polukhin P.I., Gorelik S.S., Vorontsov V.K. Fizicheskie osnovy plasticheskoy deformatsii [The physical fundamentals of plastic deformation]. - M: «Metallurgiya», 1982. - 584p. (in Russian) 
7. Khonikomb R. Plasticheskaya deformatsiya metallov [Plastic deformation of metals.]. -M: «Mir», 1972. - 408 p. (in Russian)

8. Reiner M., Levis H.K. Deformation, strain and flow. - London, 1969- 347p.

9. Trefilov V.I. Deformatsionnoe uprochnenie i razrushenie polikristallicheskikh metallov [Deformation hardening and destruction of polycrystalline metals]. - Kiev: «Naukova dumka», 1989. - 256p. (in Russian)

10. Gottshtayn G. Fiziko-khimicheskie osnovy materialovedeniya [Physicochemical fundamentals of materials science]. - Izd-vo «Binom. Laborotornye znaniya», 2016. - 400p. (in Russian)

11. Khessner F.N. Rekristallizatsiya metallicheskikh materialov [Recrystallization of metallic materials]. - M.: «Metallurgiya», 1982. - 352p. (in Russian)

12. Humphreys F.J., Hatherly M. Recrystallization and Related annealing Phenomena. -2 nd ed.-Elsevier, 2004.- 605p.

13. Gorelik S.S. Rekristallizatsiya metallov i splavov [Recrystallization of metals and alloys]. - M: «Metallurgiya», 1987. - 403p. (in Russian)

14. Polukhin P.I. Soprotivlenie plasticheskoy deformatsii metallov i splavov [Resistance to plastic deformation of metals and alloys]. - M: «Metallurgiya», 1983. - 352p. (in Russian)

15. Papirov I.I., Stoev P.I., Pikalov A.I., EmlyaninovaT.G. Study of acoustic emission during deformationof magnesium alloy // East European Journal of Physics. - 2015. - Vol.2. - No.1. - P.63-70.

16. Papirov I.I., Ivantsov V.I. Mikroplastichnost' i razmernaya stabil'nost' berilliya [Microplasticity and dimensional stability of beryllium] // Voprosy atomnoy nauki i tekhniki [Problems of atomic science and technology]. Seriya «Fizika radiatsionnykh povrezhdeniy i radiatsionnoe materialovedenie». - 1998.- Vol.6 (72). - P.121-125. (in Russian)

17. Chishko K.A. Dislokatsionnye mekhanizmy akusticheskoy emissii plasticheski deformiruemykh kristallov [Dislocation mechanisms of acoustic emission of plastically deformed crystals].- Kharkov: Preprint FTINT AN USSR, 1977- 37p. (in Russian)

18. Orowan E. A type of plastic deformation new in metals // Nature. - 1942. - Vol.149. - P.643-647.

19. Bunina N.A. Issledovanie plasticheskoy deformatsii metallov metodom akusticheskoy emissii [Investigation of plastic deformation of metals by acoustic emission method]. - L.: Izdatel'stvo Leningradskogo universiteta. 1990.-156p. (in Russian)

20. Strizhalo V.A., Dobrovol'skiy Yr.V., Strel'chenko V.A. Prochnost' i akusticheskaya emissiya materialov i elementov konstruktsiy [Strength and acoustic emission of materials and elements of constructions]. - Kiev: «Naukova dumka», 1990. 232p. (in Russian)

21. Greshnikov V.A., Drobot Yr.B. Akusticheskaya emissiya [Acoustic emission]. - M.: «Izd-vo standartov», 1976.- 272p. (in Russian)

22. Tanaka H., Horiuchi R. Acoustic emission due to deformation twinning in titanum and Ti-6Al-4V alloy // Scripta Metallurgica. - 1975. -Vol. 9. - P.777-780. 